\title{
Effect of L-arginine, dimercaptosuccinic acid (DMSA) and the association of L-arginine and DMSA on tissue lead mobilization and blood pressure level in plumbism
}

\section{C.K. Malvezzi ${ }^{1}$, \\ E.G. Moreira², I. Vassilieff', \\ V.S. Vassilieff ${ }^{2}$ \\ and S. Cordellini ${ }^{1}$}

\author{
1Departamento de Farmacologia, Instituto de Biociências, \\ Universidade Estadual Paulista, Rubião Júnior, SP, Brasil \\ ${ }^{2}$ Centro de Assistência Toxicológica (CEATOX), \\ Instituto de Biociências, U niversidade Estadual Paulista, \\ Rubião Júnior, SP, Brasil
}

\section{Correspondence \\ S. Cordellini \\ Departamento de Farmacologia Instituto de Biociências, UNESP 18618-000 Rubião Júnior, SP Brasil \\ Fax: + 55-14-6821-3744 \\ E-mail: cordelli@ ibb.unesp.br}

Research supported by CAPES. Publication supported by FAPESP.

Received April 10, 2001 Accepted July 12, 2001

\section{Abstract}

Lead $(\mathrm{Pb})$-induced hypertension is characterized by an increase in reactive oxygen species (ROS) and a decrease in nitric oxide (NO). In the present study we evaluated the effect of L-arginine (NO precursor), dimercaptosuccinic acid (DMSA, a chelating agent and ROS scavenger), and the association of L-arginine/DMSA on tissue $\mathrm{Pb}$ mobilization and blood pressure levels in plumbism. Tissue $\mathrm{Pb}$ levels and blood pressure evolution were evaluated in rats exposed to: 1) $\mathrm{Pb}$ (750 ppm, in drinking water, for 70 days), 2) Pb plus water for 30 more days, 3) Pb plus DMSA (50 mg kg${ }^{-1}$ day $\left.^{-1}, p o\right)$, L-arginine $(0.6 \%$, in drinking water), and the combination of L-arginine/DMSA for 30 more days, and 4 ) their respective matching controls. $\mathrm{Pb}$ exposure increased $\mathrm{Pb}$ levels in the blood, liver, femur, kidney and aorta. $\mathrm{Pb}$ levels in tissues decreased after cessation of $\mathrm{Pb}$ administration, except in the aorta. These levels did not reach those observed in nonintoxicated rats. All treatments mobilized $\mathrm{Pb}$ from the kidney, femur and liver. $\mathrm{Pb}$ mobilization from the aorta was only effective with the Larginine/DMSA treatment. Blood $\mathrm{Pb}$ concentrations in $\mathrm{Pb}$-treated groups were not different from those of the $\mathrm{Pb} /$ water group. $\mathrm{Pb}$ increased blood pressure starting from the 5th week. L-arginine and DMSA treatments (4th week) and the combination of L-arginine/ DMSA (3rd and 4th weeks) decreased blood pressure levels of intoxicated rats. These levels did not reach those of nonintoxicated rats. Treatment with L-arginine/DMSA was more effective than the isolated treatments in mobilizing $\mathrm{Pb}$ from tissues and in reducing the blood pressure of intoxicated rats.

The severity of the effects of, and the extent to which the cardiovascular system is affected by, lead $(\mathrm{Pb})$ appear to be influenced most directly by the $\mathrm{Pb}$ dose and the duration of $\mathrm{Pb}$ exposure. Some epidemio- logical data are compatible with the idea that chronic low-level $\mathrm{Pb}$ exposure plays a role in the development of hypertension in occupationally $\mathrm{Pb}$-exposed persons $(1,2)$ and in the general population $(3,4)$. The increased vas-
Key words

- L-arginine

- DMSA

- Tissue lead mobilization

- Plumbism

- Blood pressure

- Rat 
cular responsiveness to pressor agents is one of several factors contributing to the development of $\mathrm{Pb}$-induced hypertension (5).

Vascular endothelial and smooth muscle cells are major components of blood vessels. Endothelial cell involvement in plumbism was previously reported by Pirkle et al. (3), who suggested a blockade of nitric oxide (NO) generation in $\mathrm{Pb}$-induced hypertension. Moreover, $\mathrm{Pb}$ can block NO production in cerebral endothelial cells (6), macrophages (7), and aorta endothelial cells (8). More recently it was found that $\mathrm{Pb}$-induced hypertension in rats may be related to an increase in reactive oxygen species (ROS) (9-11).

The use of chelating agents, such as dimercaptosuccinic acid (DMSA), is the recommended therapy in heavy metal intoxication. Besides the chelating action, DMSA also presents a scavenger action of ROS (2).

Thus, the objective of the present study was to evaluate the therapeutic potential of L-arginine (the precursor of NO) and of the combination of L-arginine and DMSA on both $\mathrm{Pb}$ mobilization from tissues and blood pressure levels in plumbism.

Male Wistar rats were housed five per cage and had free access to food and water, except during testing. They were exposed to a 12-h light-dark cycle and the room temperature was controlled at $25 \pm 1^{\circ} \mathrm{C}$. The rats were provided by the animal facilities of Universidade Estadual Paulista. Animal procedures were in accordance with the guidelines for animal care prepared by the Committee on Care and Use of Laboratory Animal Resources, National Research Council, Washington DC, USA.

Animals were first exposed to $\mathrm{Pb}$ at the age of 5-6 weeks, when they weighed 150$170 \mathrm{~g}$. Experiments were performed on rats weighing 310-410 g.

The levels of $\mathrm{Pb}$ in blood, kidney, femur, liver and aorta, as well as the evolution of blood pressure were evaluated in: 1) rats exposed to $\mathrm{Pb}(750 \mathrm{ppm}$, in the form of $\mathrm{Pb}$ acetate in their drinking water ad libitum) for 70 days ( $\mathrm{Pb}$ group), and rats that received water (water group) or sodium acetate (supplying an identical amount of acetate) during the same period, 2) rats exposed to $\mathrm{Pb}$ for 70 days and then receiving water for 30 additional days ( $\mathrm{Pb} /$ water group), and rats that received water for 100 days (water group), and 3) rats exposed or not to $\mathrm{Pb}$ that later received DMSA $(25 \mathrm{mg} / \mathrm{kg}$, orally by gastric gavage, twice a day for 6 days per week) (water/DMSA or Pb/DMSA groups), L-arginine $(0.6 \%$ in their drinking water ad libitum) (water/L-arginine or $\mathrm{Pb} / \mathrm{L}$-arginine groups), and the combination of L-arginine/ DMSA (water/L-arginine/DMSA or $\mathrm{Pb} / \mathrm{L}$ arginine/DMSA groups) for 30 additional days.

One day after cessation of treatments, the animals were decapitated and trunk blood was collected for $\mathrm{Pb}$ determination. The levels of $\mathrm{Pb}$ in the kidney, femur, liver and aorta were determined in rats submitted to perfusion with heparinized saline $(0.9 \%)$ before tissue removal. $\mathrm{Pb}$ content was measured using an atomic absorption spectrometer (SpectrAA 220Z-Varian).

Systolic blood pressure was determined by tail-cuff plethysmography (Narco BioSystems, Houston, TX, USA) in conscious rats. Three measurements of blood pressure were made, and the mean of these three measurements was recorded. Blood pressure was determined before the beginning of $\mathrm{Pb}$ exposure and once a week for 70 or 100 days depending on the experimental protocol. Matching controls were used.

Results were compared by the unpaired Student $t$-test and by analysis of variance when appropriate. $\mathrm{P}<0.05$ was taken as statistically significant. The Tukey-Kramer test was used to test differences among means.

$\mathrm{Pb}$ exposure caused an increase in the levels of this metal in the blood, liver, femur, kidney and aorta (Table 1). The levels of $\mathrm{Pb}$ in tissues decreased significantly after cessation of $\mathrm{Pb}$ administration, except in the aorta 
(Table 1). However, these levels did not reach the values observed in rats not exposed to $\mathrm{Pb}$ (Table 1). The data also demonstrated that all treatments were effective in mobilizing $\mathrm{Pb}$ from the kidney, femur and liver, except for the DMSA treatment, which did not mobilize $\mathrm{Pb}$ from the femur (Table 1). However, $\mathrm{Pb}$ mobilization from the aorta was only effective with the L-arginine/DMSA treatment (Table 1). Furthermore, blood $\mathrm{Pb}$ concentrations in $\mathrm{Pb}$-treated groups were not different from those of the $\mathrm{Pb}$ /water group. An exception was the L-arginine/DMSA treatment that decreased the blood $\mathrm{Pb}$ concentration compared to the $\mathrm{Pb} /$ water group (Table 1).

In addition, $\mathrm{Pb}$ intoxication caused a significant increase in blood pressure starting on the 5th week (Figure 1). The DMSA treatment (4th week), L-arginine treatment (4th week) and the arginine/DMSA combination (3rd and 4th weeks) were effective in decreasing the blood pressure levels of rats exposed to $\mathrm{Pb}$ (Figure 1). However, these levels did not reach those of rats not exposed to $\mathrm{Pb}$ (Figure 1).

Treatment with sodium acetate did not cause any change in $\mathrm{Pb}$ mobilization or blood pressure levels of rats (data not shown).

L-arginine, DMSA, and the combination of L-arginine and DMSA treatments were more effective than the cessation of $\mathrm{Pb}$ administration in decreasing $\mathrm{Pb}$ levels in the liver, femur and kidney, although the values did not reach those observed in rats not exposed to $\mathrm{Pb}$. These data confirm previous reports demonstrating that DMSA treatment is more effective than the cessation of $\mathrm{Pb}$ administration in mobilizing $\mathrm{Pb}$ from tissues. However, depending on the dose and time of exposure, $\mathrm{Pb}$ levels may not reach those observed in rats not exposed to $\mathrm{Pb}$ $(2,12,13)$.

In contrast to what was observed in the other tissues, the combination of L-arginine and DMSA was the only effective treatment

Table 1. Tissue lead $(\mathrm{Pb})$ concentrations in rats.

\begin{tabular}{lclccc}
\hline Groups & Blood $(\mu \mathrm{g} / \mathrm{dl})$ & \multicolumn{1}{c}{ Liver $(\mu \mathrm{g} / \mathrm{g})$} & Femur $(\mu \mathrm{g} / \mathrm{g})$ & Kidney $(\mu \mathrm{g} / \mathrm{g})$ & Aorta $(\mu \mathrm{g} / \mathrm{g})$ \\
\hline Water & $<1 \mathrm{ppb}$ & $0.03 \pm 0.01$ & $0.13 \pm 0.02$ & $0.17 \pm 0.03$ & $0.11 \pm 0.01$ \\
$\mathrm{~Pb}$ & $67.80 \pm 10.28$ & $1.86 \pm 0.12^{*}$ & $162.94 \pm 6.75^{*}$ & $93.29 \pm 3.22^{*}$ & $0.25 \pm 0.02^{*}$ \\
$\mathrm{~Pb} /$ water & $11.15 \pm 1.64^{\ddagger}$ & $0.21 \pm 0.03^{* \ddagger}$ & $133.73 \pm 6.24^{* \ddagger}$ & $23.57 \pm 0.83^{* \ddagger}$ & $0.20 \pm 0.03^{*}$ \\
& & & & & \\
Water/DMSA & $<1 \mathrm{ppb}$ & $0.02 \pm 0.01^{+}$ & $0.06 \pm 0.01^{*+}$ & $0.14 \pm 0.02^{+}$ & $0.12 \pm 0.01^{+}$ \\
$\mathrm{Pb} / \mathrm{DMSA}$ & $13.77 \pm 0.89$ & $0.10 \pm 0.01^{*+\#}$ & $110.03 \pm 13.21^{* \#}$ & $5.14 \pm 0.46^{*+\#}$ & $0.20 \pm 0.04^{*}$ \\
Water/L-Arg & $1.24 \pm 0.73^{+}$ & $0.03 \pm 0.01^{+}$ & $0.05 \pm 0.01^{*+}$ & $0.04 \pm 0.01^{*+}$ & $0.11 \pm 0.01^{+}$ \\
Pb/L-Arg & $11.62 \pm 0.86^{\#}$ & $0.12 \pm 0.02^{*+\#}$ & $26.55 \pm 0.80^{*+\#}$ & $8.10 \pm 1.48^{*+\#}$ & $0.21 \pm 0.05^{*}$ \\
Water/L-Arg/ & $0.19 \pm 0.19^{+}$ & $0.03 \pm 0.01^{+}$ & $0.07 \pm 0.01$ & $0.04 \pm 0.01^{*+}$ & $0.07 \pm 0.01^{+}$ \\
DMSA & & & & & \\
Pb/L-Arg/DMSA & $6.14 \pm 1.34^{+\#}$ & $0.12 \pm 0.01^{*+\#}$ & $57.04 \pm 8.92^{*+\#}$ & $7.26 \pm 0.97^{*+\#}$ & $0.13 \pm 0.01^{*+\#}$ \\
\hline
\end{tabular}

Water: rats not exposed to lead; $\mathrm{Pb}$ : rats exposed to $750 \mathrm{ppm} \mathrm{Pb}$ in drinking water ad libitum for 70 days; water/DMSA, water/L-Arg and water/L-Arg/DMSA: rats not exposed to $\mathrm{Pb}$ that received dimercaptosuccinic acid (DMSA), L-arginine (L-Arg) and the combination of L-Arg and DMSA, respectively, for 30 days; Pb/water, $\mathrm{Pb} / \mathrm{DMSA}, \mathrm{Pb} / \mathrm{L}-\mathrm{Arg}$ and $\mathrm{Pb} / \mathrm{L}-\mathrm{Arg} / \mathrm{DMSA}$ : rats exposed to $\mathrm{Pb}$ for 70 days that received $\mathrm{DMSA}, \mathrm{L}-\mathrm{Arg}$ and the combination of L-Arg and DMSA, respectively, for 30 additional days. Values are reported as means \pm SEM $(\mathrm{N}=4-10)$

$* P<0.05$ compared to water.

$+\mathrm{P}<0.05$ compared to $\mathrm{Pb} /$ water. This comparison was not possible with water/DMSA in blood.

\# $<0.05$ for $\mathrm{Pb} /$ treatment compared to the respective water treatment. This comparison was not possible with DMSA treatment in blood.

$\ddagger \mathrm{P}<0.05$ for $\mathrm{Pb} /$ water compared to $\mathrm{Pb}$ (ANOVA and Tukey-Kramer test). 
Figure 1. Weekly evolution of blood pressure. A, Rats exposed to $750 \mathrm{ppm}$ lead in drinking water ad libitum for 70 days (Pb) and rats that later received water for the same period of time (water). B, C, D, Rats exposed or not to $\mathrm{Pb}$ for 70 days that later received DMSA (water/DMSA, $\mathrm{Pb} / \mathrm{DMSA}$ ), L-arginine (water/LArg, $\mathrm{Pb} / \mathrm{L}-\mathrm{Arg}$ ), and the combination of L-Arg and DMSA (water/ L-Arg/DMSA, Pb/L-Arg/DMSA) for 30 additional days. Values are reported as means \pm SEM ( $N=$ 6). $* \mathrm{P}<0.05$ for $\mathrm{Pb} /$ treatment compared to water; $+\mathrm{P}<0.05$ for $\mathrm{Pb} /$ treatment compared to $\mathrm{Pb} /$ water (Student t-test and ANOVA followed by the TukeyKramer test).
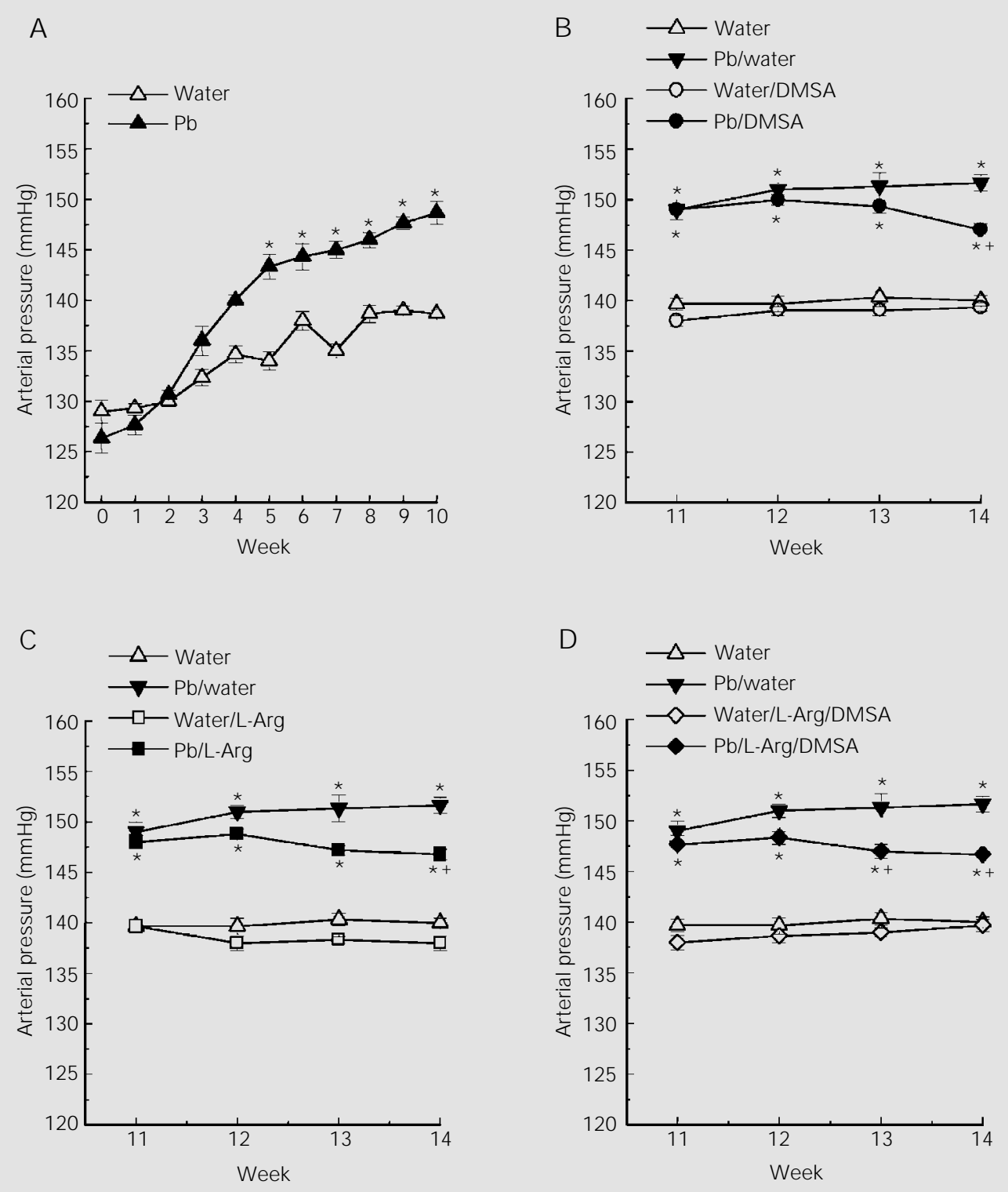

in reducing the $\mathrm{Pb}$ levels of the aorta and of the blood of intoxicated rats. However, these levels did not reach those observed in nonintoxicated rats. The mobilization of $\mathrm{Pb}$ from tissues favors its redistribution. This may explain, the maintenance of high levels of $\mathrm{Pb}$ in blood after the DMSA and the L-arginine treatments which were capable of mobilizing $\mathrm{Pb}$ from tissues. The high levels of $\mathrm{Pb}$ in blood under these conditions may also explain the non-mobilization of $\mathrm{Pb}$ from the aorta. This hypothesis is reinforced by the observation that the combination of L-arginine and DMSA, which caused a significant decrease in $\mathrm{Pb}$ levels in blood, was capable of reducing $\mathrm{Pb}$ levels in the aorta. It should be pointed out that the present study is the first report in the literature showing that Larginine is an effective agent in mobilizing $\mathrm{Pb}$ from tissues, including bone tissue. The literature has shown that sulfur amino acids such as methionine and cysteine, and amino acids metabolically related to them, increase the bioavailability of glutathione, which is 
useful in chelating $\mathrm{Pb}$, counteracting the toxic effects of the metal and may be used as supportive therapy $(14,15)$. Moreover, in metalloregulatory proteins, metals are often conveniently located at binding sites and bound to cysteine residues. Several lines of evidence indicate that cysteine-rich metalbinding proteins, as well as redox-sensitive metal clusters of metalloproteins, are natural sensors of bioradicals like NO (16). In addition, Misra et al. (17) showed that NO mediates cadmium release from metallothionein. Thus, an increase in NO levels by L-arginine treatment might displace $\mathrm{Pb}$ from its cell binding sites.

The sustained increase in systolic blood pressure observed in rats treated with $\mathrm{Pb}$ for 70 days confirms previous reports in the literature showing that arterial hypertension is associated with plumbism $(2,3)$. The combination of L-arginine and DMSA induced an earlier decrease in the blood pressure of $\mathrm{Pb}$-intoxicated rats compared to the isolated treatments. One possible explanation would be the additional effect of L-arginine, the NO precursor (18), and the effects of DMSA, a chelating agent and scavenger of ROS
$(2,19)$, on blood pressure. However, no treatment was effective in normalizing the blood pressure of $\mathrm{Pb}$-intoxicated rats, in contrast to literature reports showing that DMSA treatment is capable of abolishing $\mathrm{Pb}$-induced hypertension $(2,20)$. This discrepancy may be due to differences in the protocols related to the doses and duration of the treatment, since it was previously reported that these parameters are important in reversing $\mathrm{Pb}$ induced hypertension (12).

The present study showed 1) the action of L-arginine as a $\mathrm{Pb}$ chelator, and 2) an anticipation in the reversal of the blood pressure levels, as well as a larger mobilization of $\mathrm{Pb}$ from the aorta and blood with the combination of L-arginine and DMSA compared to the isolated treatments. These observations suggest a therapeutic potential for the combination of L-arginine and DMSA in plumbism.

\section{Acknowledgments}

The authors acknowledge the expert technical assistance of Ana Maria Seraphim.

\section{References}

1. Selevan SG, Landrigan PJ, Stern FB \& J ones J H (1985). Mortality of lead workers. American J ournal of Epidemiology, 122: 673-683.

2. Khalil-Manesh F, Gonick HC, Weiler EWJ , Prins B, Weber MA, Purdy R \& Ren Q (1994). Effects of chelation treatment with dimercaptosuccinic acid (DMSA) on lead-related blood pressure changes. Environmental Research, 65: 86-99.

3. Pirkle J L, Schwartz J , Landis J R \& Harlan WR (1985). The relationship between blood lead levels and blood pressure and its cardiovascular risk implications. American J ournal of Epidemiology, 121: 246258.

4. Bost L, Primatesta P, Dong W \& Poulter N (1999). Blood lead and blood pressure: evidence from the Health Survey for England. J ournal of Human Hypertension, 13: 123-128.
5. Skoczynska A, J uzwa W, Smolik R, SzechinskiJ \& Begal FJ (1986). Response of the cardiovascular system to catecholamines in rats given small doses of lead. Toxicology, 39: 275-289.

6. Mittal CK, Harrell WB \& Mehta CS (1995). Interaction of heavy metal toxicants with brain constitutive nitric oxide synthase. Molecular and Cellular Biochemistry, 149: 263-265.

7. Tian L \& Lawrence DA (1995). Lead inhibits nitric oxide production in vitro by murine splenic macrophages. Toxicology and Applied Pharmacology, 132: 156-163.

8. Kaji T, Fujiwara $Y$, Hoshino M, Yamamoto C, Sakamoto M \& Kozuka H (1995). Inhibitory effect of lead on the proliferation of cultured vascular endothelial cells. Toxicology, 95: 87-92.

9. Gonick HC, Ding Y, Bondy SC, Ni Z \& Vaziri ND (1997). Lead-induced hyperten- sion. I. Interplay of nitric oxide and reactive oxygen species. Hypertension, 30: 1487-1492.

10. Vaziri ND, Liang K \& Ding Y (1999). Increased nitric oxide inactivation by reactive oxygen species in lead-induced hypertension. Kidney International, 56: 1492-1498.

11. Ding Y, Gonick HC \& Vaziri ND (2000). Lead promotes hydroxyl radical generation and lipid peroxidation in cultured aortic endothelial cells. American J ournal of Hypertension, 13 (Part 1): 552-555.

12. Pappas J B, Ahlquist J T, Allen EM \& Banner J r W (1995). Oral dimercaptosuccinic acid and ongoing exposure to lead: effects on heme synthesis and lead distribution in a rat model. Toxicology and Applied Pharmacology, 133: 121-129.

13. Tandon SK, Singh S, Prasad S \& Mathur N (1998). Mobilization of lead by calcium 
versenate and dimercaptosuccinate in the rat. Clinical and Experimental Pharmacology and Physiology, 25: 686-692.

14. Kachru DN, Khandelwal S \& Tandon SK (1989). Influence of methionine supplementation in chelation of lead in rats. Biomedical and Environmental Sciences, 2: 265-270.

15. Quig D (1998). Cysteine metabolism and metal toxicity. Alternative Medicine Review, 3: 262-270.

16. Drapier J C \& Bouton C (1996). Modula- tion by nitric oxide of metalloprotein regulatory activities. Bioessays, 18: 549-556.

17. Misra RR, Hochadel J F, Smith GT, Cook J C, Waalkes MP \& Wink DA (1996). Evidence that nitric oxide enhances cadmium toxicity by displacing the metal from metallothionein. Chemical Research in Toxicology, 9: 326-332.

18. Mayer B \& Hemmens B (1997). Biosynthesis and action of nitric oxide in mammalian cells. Trends in Biochemical Sciences, 22: 477-481.
19. Cory-Slechta DA (1988). Mobilization of lead over the course of DMSA chelation therapy and long term efficacy. J ournal of Pharmacology and Experimental Therapeutics, 245: 84-91.

20. Ding Y, Vaziri ND \& Gonick HC (1998). Lead-induced hypertension. II. Response to sequential infusions of L-arginine, superoxide dismutase, and nitroprusside. Environmental Research, 76: 107-113. 